\title{
The Evolution of Pediatric Practice
}

\author{
Shilpa Aroskar
}

MGM Hospital, Vashi, Navi Mumbai, India

\section{Article Info}

\section{Article Notes}

Received: January 11, 2019

Accepted: April 29, 2019

\section{*Correspondence:}

Dr. Shilpa Aroskar, Consultant Pediatrician, MGM Hospital, Vashi, Navi Mumbai, India; Email: sparoskar@hotmail.com.

C) 2019 Aroskar S. This article is distributed under the terms of the Creative Commons Attribution 4.0 International License.
"Digital Darwinism is the evolution of consumer behavior when society and technology evolve faster than your ability to adapt."

I was on my morning rounds at the hospital. While examining a complex case, I asked my resident doctors to fetch Nelson textbook of pediatrics (Bible of pediatrics) from the ward. My grey cells were amnestic about the pathophysiology of the disease of this not so common a case. My whole unit was instantly glued to their smartphones in a jiffy. They were uploading on google and enlightening me with quantum of information that the windows of my brain could not download it in one go. Whoa!!

Should I have been happily impressed at this digital decoding? I was not. I missed the feel of those pages, the fine print, the underlined lines with a marker pen and the nostalgia of spending half a lifetime submerged in those books. I do sound like belonging to the old school as compared to the new Gen X.

But it just made me ponder how long we have come in practicing the Art of Medicine and how much our patients or parents to be precise have changed in the last two decades?

I remember my residency days, a not so digital era-where I used a fountain pen to chart patients notes, drawing those family pedigree charts, measuring anthropometry and then patiently plotting the centiles with marker pen on growth charts . Calculating calories for diet chart or the drug dosages which were so well imbibed in our brain. All these manually sans any apps or calculators. There were no pagers and no cell phones so the ward assistants would come to the on-call room with a hand written call on a book, which we would sign. In case if one goes back to sleep the sign would be a proof for your summons the next day. This has been replaced now with E-prescriptions, document templates, readymade drug calculators, growth chart apps, metrics, and EHRs. Pen and paper have become redundant. Doctors sit with i-pads in their offices and often the disease and its course is run as a short documentary 3D movie on their gadgets petrifying the patients. Patients are offered multiple menu of therapy to choose from, leaving them baffled as to which flavor would suit the palate and the pocket both. While evolution is good and being tech savvy makes you look like a "smart doctor" to the smartphone user clientele but somewhere down the line, I feel we are losing human "touch" and "empathy "to be precise.

A pat on the ailing patient's hand to comfort him, few kind words of hope that everything is going to be fine, relying more on our clinical methods and less on the reports, and lastly, I feel offering one apt rational therapy is what we were taught in medical school. 
And let's not talk about "Robots "in the hospital!! May be by 2030 we will have more of Robots and less of doctors everywhere in our hospitals from inserting central lines in ICUs, performing surgeries in ORs and even taking bedside rounds with a stethoscope and handing a prescription. Where would we fit in then? They may be better skilled than the human hand but will there be a healing touch, a hand to wipe not swipe a tear or a comforting confident smile from your doctor which is assertive enough to say that you are in safe hands. How can we heal without the basic juice of human survival-Emotions!!!

I am sure if Adam and Eve were alive then they would have been crestfallen about their progeny being replaced by Robots.

Now let's see the other side of the coin. Parents have taken a leap of evolution too in the last two decades. The child-bearing age has shifted to 28 to 35 in urban areas. So, these parents are raised in an era different than mine and yours where they can't recall not booking movie tickets on line or not able to order food on swiggy. The good old family doctor has been replaced by smart (digitally as well as smartly attired) consultant sitting in plush leather chairs in five-star corporate hospitals. Everything has to appeal first to the eyes of the parents from the ambience of your clinic, to smiling soft spoken secretaries to your own self. Your attire and body language have to evoke that confidence in the parents that yes, we are in the right hands. Knowledge and experience come later. Also, you are already scrutinized and your resume is viewed, number of likes you have received and comments and Google rating -all scanned by the time the parents come to seek your expertise.

Then they address you as "Hey Doc "if you are lucky or mostly by your first name. They open their gadgets and are ready to take your 'viva' with all the knowledge(illusion of knowledge ) they have acquired from Dr. Google. You have to patiently answer with a serene smile on your face and mind you there is no extra fees for this extra time. Pathology reports are bought on their smartphones and at times even $\mathrm{X}$-ray pictures. And yes, remember to spell check the child's name when you enter in your data it might have few extra "a and $\mathrm{m}$ " as per the auspicious numerology securing the good fortune of their child.

Parenting in modern era can be competitive when each couple is aspiring to raise a perfect child physically and mentally...Then there is a quantum of information shared on FB groups -First Moms Club or New Dads in The making groups where food recipes, organic to gluten free, child's milestones, sleeping patterns, and how to improve the child's IQ etc. are shared during lunch breaks in offices. Weekends are spent in attending various parenting workshops.. Seldom do they realize that "children are not things to be molded but people to be unfolded."

Love for their children is flaunted in "tattoos' pierced on the hands of parents. DQ and IQ of their child are proudly measured by how smartly the child can operate all the apps on their smartphones. Lullaby is being sung by Samsung and Apple and Mothers "lap" to read bedtime stories is replaced by "App" like kindle. Childs activities during the day are monitored on parent's smartphones in offices with cameras in the daycare centers.

Trust and respect are in paucity with the Millennial parents. They are mostly dubious about everything you say and indulge in doctor shopping. Then there are helicopter parents who hover all the time on them often not giving the child a chance to talk in the Doctor's office and boomer parents who are struggling with the fine art of letting go of their adolescents.

Parenting today has become a predictable protocolbased software and the subtle surprises and joy of upbringing a child is being given a sad miss.

Digital Darwinism has to some extent taken away the charm of practicing pediatrics. It's more of a consumer provider paid healthcare system, a demand and supply where respect, trust, ethics, morals and empathy all are becoming elusive.

Yes, we have definitely come a long way and like it or not we need to embrace this change, burgeoning the new technology, adapt and learn to survive to sustain our practices else we are snapped trapped. While the basic fundamentals of parenting will cease to change and be quintessential, the nuances will evolve and "affluenza "will soon be like a plague in corporate healthcare. Electronic grooming is a double-edged weapon both disruptive and useful with its own opportunities and challenges.

We need to master the subtle art of when to let go and how much change to adapt for the sanity and dignity of our profession.

\section{As rightly said}

"The art of practicing medicine is to entertain the relatives while nature itself heals the diseases holds true in these changing times."

And yes, in this digitalization era even if you ask God to "save" you from such patients the reply may be "JPEG OR PDF which format my child?" 